\title{
EFFICACY OF IONIC LIQUID [MIM]BR-BASED MAE ON RESVERATROL AND PHENOLIC COMPOUNDS EXTRACTION FROM GNETUM GNEMON SEEDS AND THEIR DPP-4 INHIBITORY ACTIVITY
}

\author{
ARIF ARRAHMAN ${ }^{1}$, REZI RIADHI SYAHDI ${ }^{2}$, HANA PERMATASARI ${ }^{2}$, INTAN FIKRI PURNAMA SARI ${ }^{2}$, \\ ABDUL MUNIM ${ }^{2 *}$
}

\begin{abstract}
${ }^{1}$ Department of Pharmaceutical-Medicinal Chemistry and Bioanalysis, Faculty of Pharmacy, Universitas Indonesia, Depok 16424, Indonesia. ${ }^{2}$ Department of Pharmacognosy-Phytochemistry, Faculty of Pharmacy, Universitas Indonesia, Depok 16424, Indonesia. Email: munim@farmasi.ui.ac.id
\end{abstract}

Received: 04 June 2018, Revised and Accepted: 06 August 2018

\section{ABSTRACT}

Objective: This study aimed to determine the inhibitory activity of 1-butyl-3-methylimidazolium bromide ([bmim]Br) extracts of melinjo seeds (Gnetum gnemon) on dipeptidyl peptidase-4 (DPP-4).

Methods: Melinjo seeds were extracted by a [bmim]Br microwave-assisted method using various extraction parameters and the inhibitory activity of DPP-4 of all extracts was determined in 96-well microplates using Cayman inhibitor screening assay. Determination of trans-resveratrol content was conducted using a reverse-phase high-performance liquid chromatography method. The total phenolic content was determined using a 96-well microplate reader. Data analysis for the determination of the optimal extraction conditions was developed by response surface methodology.

Results: The extract obtained from the third run showed the highest inhibition (28.73\%) against DPP-4 activity with the total phenolic content of $1.96 \mathrm{mg}$ gallic acid equivalent/g the seed powder.

Conclusion: The analytical results revealed the following optimal conditions: Solvent concentration 1.5 M, liquid-solid ratio 23:1, and extraction time $15 \mathrm{~min}$.

Keywords: Gnetum gnemon, [bmim]Br, Trans-resveratrol, Microwave-assisted extraction, Dipeptidyl peptidase-4, Phenolic content.

(c) 2018 The Authors. Published by Innovare Academic Sciences Pvt Ltd. This is an open access article under the CC BY license (http://creativecommons. org/licenses/by/4. 0/) DOI: http://dx.doi.org/10.22159/ijap.2018.v10s1.36

\section{INTRODUCTION}

Diabetes mellitus is a metabolic disorder characterized by high blood sugar levels. Metabolic disorders are usually accompanied by disorders of lipid, carbohydrate, and protein metabolism caused by insulin resistance and insulin deficiency [1]. The classes of therapeutics currently used for these conditions, such as sulfonylureas, biguanides, and $\alpha$-glucosidase inhibitors, have the major side effects of weight gain and hypoglycemia [2]. It has recently been observed that dipeptidyl peptidase-4 (DPP-4) may be used as an antidiabetic and a newer target for diabetic therapy [3]. In previous research, extracts containing polyphenols were revealed to have activity as DPP-4 inhibitors [4-6]. Resveratrol is a member of the polyphenol group of stilbenes that have various pharmacological activities, especially in trans-resveratrol isomer form including antioxidant, anti-inflammatory, antitumor, cardiovascular protective, anticancer, and antidiabetic effects [7-11]. Several species of the genus Gnetum are known to contain resveratrol and its derivatives in quantities sufficient to exhibit physiological effects [12]. One of those plants is Gnetum gnemon L. or locally known as melinjo, which widely cultivated in Southeast Asia [13]. Kato et al. found that melinjo seed extract contains various stilbenoids including resveratrol, gnetin $\mathrm{C}$, gnetin $\mathrm{L}$, gnemonoside $\mathrm{A}$, gnemonoside $\mathrm{C}$, and gnemoside D [14].

Resveratrol has been successfully extracted from various plants by conventional approaches using organic solvents. However, these extraction methods are considered neither efficient nor environmentfriendly. In contrast, ionic liquid-microwave-assisted extraction (IL-MAE) is a new extraction method that is environmentally friendly and uses a microwave as a heat source and ionic liquid for solvent extraction. MAE has several advantages such as its brief extraction time, small amount of solvent used, and high efficiency compared with other conventional extraction methods. ILs also have several advantages such as high conductivity, very low vapor pressure, adjustable, an environmentally friendly nature, and being able to efficiently absorb microwave energy compared with organic solvents $[7,15,16]$. Based on studies reported in the literature, ILs-MAE has been developed for trans-resveratrol extraction from Polygonum cuspidatum roots (2007) and Smilax china (2009) by Du et al. $[17,18]$. The results showed that the best IL for trans-resveratrol extraction from both of these plants was 1-butyl-3-methylimidazolium bromide ([bmim]Br). However, to the best of our knowledge, no studies have focused on [bmim] Br in trans-resveratrol extraction from melinjo (Gnetum gnemon L.) seeds by an MAE method. As the capacity of this MAE method can be affected by various factors, trans-resveratrol extraction from melinjo seeds using [bmim] Br with MAE should be optimized, which can be achieved using response surface methodology (RSM).

\section{METHODS}

\section{Sample preparation}

Melinjo (Gnetum gnemon L.) seeds were purchased from a traditional market in Pandeglang, Banten, Indonesia. Seeds that were still covered with hard skin were dried, and the hard skin was peeled away. The dried seeds covered with epidermis were powdered using a commercially available kitchen blender.

\section{Chemicals used}

The ionic liquid 1-butyl-3-methylimidazolium bromide/[bmim]Br was obtained from Chengjie Chemical Co., Ltd. (China). Standard resveratrol was purchased from Wako, Japan. Gallic acid, Folin-Ciocalteu P, and $\mathrm{Na}_{2} \mathrm{CO}_{3}$ were obtained from Sigma-Aldrich, Japan. Meanwhile, ethyl acetate and deionized water were obtained from Brataco, Indonesia. Methanol pro analysis, acetonitrile (high-performance liquid chromatography [HPLC] grade), and acetic acid were purchased from Merck, Germany. A PVDF microporous membrane filter of $0.45 \mu \mathrm{m}$ was purchased from Agilent, USA, and aqua bidest was obtained from Ikapharmindo, Indonesia. 
Experimental design and statistical analysis

RSM was employed in this study for experimental design, data analysis, model building, and analysis, with suggestions for optimal conditions also being given with the software Design Expert (v.10.0.3). Three factors with three levels were studied with a Box-Behnken design (BBD) to determine the number of tests and variations in combination, establish a model, and estimate the interactions between factors and process parameters. The independent factors were IL concentration (1.5, 2.0, and 2.5 M), extraction time $(10,12.5$, and $15 \mathrm{~min})$, and solventto-sample ratio $(18,20.5$, and $23 \mathrm{~mL} / \mathrm{g})$. The ranges of experimental values for the independent factors in this study are given in Table 1. Meanwhile, the response variable in this experiment was transresveratrol content ( $\mathrm{mg} / \mathrm{g}$ melinjo seed powder).

Each extraction was performed using $1 \mathrm{~g}$ of melinjo seed powder placed in a flat-bottomed flask and immersed in the ionic liquid [bmim] Br for $1 \mathrm{~h}$ in the dark before the extraction process. The extraction was performed based on the results of an experimental design using a BBD (Table 2) at microwave power of $30 \%$ (P 30\%), which was consistently selected. After the extraction process had been completed, the mixture of ionic liquid and extract was cooled to room temperature and centrifuged at $3000 \mathrm{r} / \mathrm{min}$ for $15 \mathrm{~min}$. Finally, the obtained supernatant was filtered, and the volume was measured. The fraction was obtained from the supernatant by adding $\mathrm{Na}_{2} \mathrm{CO}_{3}$ solution $(0.01 \mathrm{~mol} / \mathrm{l})$ and extracted using ethyl acetate. All of the upper phases were collected and evaporated in an oven at $40^{\circ} \mathrm{C}$. Dried extracts were weighed, and percentage yield extraction was calculated by dividing mass of dried extract (mg) with mass of raw material (mg), then times 100\%.

\section{Determination of total phenolic content}

The total phenolic content was determined using Folin-Ciocalteu reagent with a microplate reader as reported by Bobo-García et al. with slight modification [19]. Dried extract was diluted in $5 \mathrm{~mL}$ of methanolwater $(1: 1 \mathrm{v} / \mathrm{v})[20]$. Each extract solution was pipetted $(20 \mu \mathrm{L})$ into a 96-well microplate and supplemented with $100 \mu \mathrm{L}$ of Folin-Ciocalteu reagent $(1: 4 \mathrm{v} / \mathrm{v})$; the mixture was shaken for $1 \mathrm{~min}$ in a microplate reader and then left for $4 \mathrm{~min}$ at room temperature. After that, $75 \mu \mathrm{L}$ of $\mathrm{Na}_{2} \mathrm{CO}_{3}$ solution $(100 \mathrm{~g} / \mathrm{l})$ was added to the mixture, which was then shaken for $1 \mathrm{~min}$. After $2 \mathrm{~h}$, the absorbance was measured using a microplate reader at a UV wavelength of $750 \mathrm{~nm}$. Gallic acid solutions (25-400 mg/l) were used as standards for calibration. This method was repeated 3 times for the same solution. The results are expressed as $\mathrm{mg}$ gallic acid equivalent (GAE)/g melinjo seed powder.

\section{DPP-4 assay}

This assay was performed in 96-well microplates. Cayman's DPP-4 inhibitor screening assay provides a convenient fluorescence-based method for screening DPP-4 inhibitors. The assay uses the fluorogenic substrate, Gly-Pro-aminomethylcoumarin (AMC), to measure DPP-4 activity. Cleavage of peptide bonds by DPP releases a free AMC group, resulting in fluorescence that can be analyzed using an excitation wavelength of 350-360 $\mathrm{nm}$ and an emission wavelength of 450-465 nm. The samples were reconstituted in assay buffer to a concentration of $100 \mathrm{mg} / \mathrm{l}$ (stock solution concentration).

\section{Determination of trans-resveratrol using HPLC}

The same extract solution for total phenolic compounds was filtrated through a $0.45 \mu \mathrm{m}$ microporous membrane for subsequent HPLC analysis. HPLC analysis was performed with isocratic elution and a flow rate of $1.0 \mathrm{~mL} / \mathrm{min}$. The mobile phase consisted of $\mathrm{H}_{2} \mathrm{O}$-acetonitrile $(75: 25 \mathrm{v} / \mathrm{v})$. The solution was adjusted to $\mathrm{pH} 3$ with $\pm 5 \mathrm{~mL}$ acetic acid. The injection volume was $20 \mu \mathrm{L}$ injected through a $20 \mu \mathrm{L}$ loop into a Zorbax reverse-phase C18 column, and the UV detector was operated at $306 \mathrm{~nm}$ [21]. Trans-resveratrol in each extract was identified by comparing the retention time with the reference standard. Transresveratrol concentration in each extract was measured using the calibration curve of resveratrol standards $(1-15 \mu \mathrm{g} / \mathrm{mL})$.

\section{RESULTS AND DISCUSSION}

\section{Total phenolic content}

The determination of total phenolic content in melinjo seed extract from IL-MAE was performed using the Folin-Ciocalteu method, with a microplate reader as an instrument that can be used rapidly and consume less solvent, along with gallic acid as a standard solution due to it being used for the unit of phenolic compounds [3]; this structure has a hydroxyl group and a conjugated double bond on each of the benzene rings, making it directly react to form a complex with the Folin-Ciocalteu reagent [3]. A calibration curve was made in the concentration range of $25-400 \mathrm{mg} / \mathrm{l}$, obtaining a linear regression equation of $\mathrm{y}=0.0084 \mathrm{x}+0.1689$, with $\mathrm{R}^{2}=0.9992$. The results showed that total phenolic content in melinjo seed powder ranged from 0.4546 to $1.9562 \mathrm{mg} \mathrm{GAE} / \mathrm{g}$ of melinjo seed powder. The highest total phenolic content in melinjo seed powder was $2.0128 \mathrm{mg} \mathrm{GAE} / \mathrm{g}$ of melinjo seed powder, which occurred in run 6. Run 6 involved the following MAE conditions: [bmim] Br concentration $2.5 \mathrm{M}$, solvent-to-sample ratio 20.5:1, and extraction time $15 \mathrm{~min}$.

In this study, the results of total phenolic content in Gnetum gnemon seed extract from the IL-MAE method (ranging from 0.4546 to $1.9562 \mathrm{mg} \mathrm{GAE} / \mathrm{g}$ of melinjo seed powder) were lower than the results from Gnetum gnemon seeds extracted using reflux with 95\% ethanol (6.49 GAE/g, freeze-dried weight of the seeds) [22].

\section{DPP-4 assay}

The 17 extracts were analyzed for DPP-4 inhibitory activity, the results of which are summarized in Table 3 . The highest inhibitory rate was achieved in the third run, at $28.78 \%$, which involved the extraction for $15 \mathrm{~min}$ with a solvent concentration of $1.5 \mathrm{M}$ as much as $20.5 \mathrm{~mL}$. The results revealed inhibitory activity against DPP-4, which may indicate

Table 1: Experimental factor levels for the RSM study in the BBD

\begin{tabular}{lllc}
\hline Factor & Notation & Range and levels \\
\cline { 2 - 4 } & & $\mathbf{- 1}$ & $\mathbf{0}$ \\
\hline$\left(X_{1}\right)$ Ionic liquid [bmim]Br concentration & mol/l & 1.5 & 2.0 \\
$\left(X_{2}\right)$ Extraction time & min & 10 & 12.5 \\
$\left(X_{3}\right)$ Solvent-to-sample ratio & mL/g & 18 & 20.5 \\
\hline
\end{tabular}

BBD: Box-Behnken design, RSM: Response surface methodology

Table 2: Pipetting summary

\begin{tabular}{lllll}
\hline Well & Assay buffer $(\boldsymbol{\mu L})$ & DPP-4 $(\boldsymbol{\mu L})$ & Solvent $(\boldsymbol{\mu L})$ & Inhibitor $(\boldsymbol{\mu L})$ \\
\hline $100 \%$ initial activity & 30 & 10 & 10 & - \\
Background & 40 & - & 10 & - \\
Sitagliptin & 30 & 10 & - & 50 \\
Inhibitor & 30 & 10 & - & 50 \\
\hline
\end{tabular}


therapeutic potential against type 2 diabetes. The $50 \%$ inhibitory concentration $\left(\mathrm{IC}_{50}\right.$ ) of sitagliptin as a standard was $22 \mathrm{nM}$, whereas based on previous research, it was $19 \mathrm{nM}$. Sitagliptin phosphate exhibits a potent inhibitory effect on DPP-4, with an $\mathrm{IC}_{50}$ of $19 \mathrm{nM}$, for Caco-2 cell extracts [23]. In a study by Fan et al., 2014 phenolic compounds were tested, revealing that anthocyanins were the most potent at DPP-4 inhibition [24]. There are more phenolic compounds that have potent effects of this type, such as resveratrol $\left(\mathrm{IC}_{50}, 0.6 \pm 0.4 \mathrm{nM}\right)$, luteolin $(0.12 \pm 0.01 \mu \mathrm{M})$, apigenin $(0.14 \pm 0.02 \mu \mathrm{M})$, and flavone $(0.17 \pm 0.01$ $\mu \mathrm{M})$. The resveratrol presents in melinjo seed extract can impart a significant antidiabetic effect. Melinjo seed extract also contains tannin, which is known to have an inhibitory effect on DPP-4, so it can be concluded that inhibition of DPP-4 activity is not only caused by resveratrol. In this study, the third run, which was not the sample with the highest resveratrol content, could inhibit DPP-4 better than other samples. However, resveratrol also has an inhibitory effect on DPP-4, as shown by the percentage inhibition achieved by resveratrol standard $100 \mathrm{mg} / \mathrm{l}$ (concentration of stock solution) of $23.52 \%$. This is also supported by a previous study, which explained that resveratrol has an antihyperglycemic effect on DPP-4, which increases the level of incretins followed by lowering of the blood glucose level [25]. Administration of DPP-4 inhibitors prolongs the half-life glucagon-like peptide-1 and glucose-dependent insulinotropic peptide, thus it is used as the newest pharmaceutical targets for type II diabetes treatment [26].

\section{Determination of trans-resveratrol content}

The method for analyzing trans-resveratrol involved the use of HPLC by analyzing standard and samples. First, qualitative identification was performed based on comparison of their retention times $\left(t_{R}\right)$. The retention time of resveratrol standard was $8 \mathrm{~min}$. Quantitative identification was based on peak area that was plotted in a calibration curve with a linear equation of $y=33194+149376 x,\left(R^{2}=0.9995\right)$, where $\mathrm{y}$ is the peak area and $\mathrm{x}$ is trans-resveratrol concentration (in $\mathrm{mg} / \mathrm{l}$ ). The results of trans-resveratrol content from all runs are shown in Table 2 (column 5). The results showed that trans-resveratrol content from 17 extraction runs ranged from 0.0309 to $0.0749 \mathrm{mg} / \mathrm{g}$ melinjo seed powder. The results showed that resveratrol content from Gnetum gnemon seeds from ionic liquid [bmim]Br extract $[0.0749 \mathrm{mg} / \mathrm{g}$ melinjo seed powder) was lower than for P. cuspidatum rhizome $(2.487 \mathrm{mg} / \mathrm{g}$ rhizome dried powder) ionic liquid extract extracted with the same ionic liquid ([bmim]Br) and extraction technique (microwave-assisted extraction) [17]. This difference could have occurred because there were differences in the matrix and plant material used in the ionic liquid-based microwave-assisted extraction process [27].

Table 3: Resveratrol content, total phenolic content, and percentage DPP-4 inhibition in 17 samples

\begin{tabular}{|c|c|c|c|c|c|c|}
\hline \multirow[t]{2}{*}{ Sample } & \multicolumn{3}{|l|}{ Extraction conditions } & \multicolumn{3}{|l|}{ Analysis } \\
\hline & $\begin{array}{l}{[\mathrm{bmim}] \mathrm{Br}} \\
\text { concentration }(\mathrm{mol} / \mathrm{L})\end{array}$ & $\begin{array}{l}\text { Solvent-to-sample } \\
\text { ratio }(\mathrm{mL} / \mathrm{g})\end{array}$ & $\begin{array}{l}\text { Extraction } \\
\text { time (min) }\end{array}$ & $\begin{array}{l}\text { Resveratrol content } \\
\text { (mg/gram melinjo } \\
\text { seed powder) }\end{array}$ & $\begin{array}{l}\text { Total phenolic content } \\
\text { (mg GAE/g melinjo } \\
\text { seed powder) }\end{array}$ & $\begin{array}{l}\text { \% inhibition } \\
\text { DPP-4 }\end{array}$ \\
\hline 1 & 2.5 & 18 & 12.5 & 0.0385 & 1.000 & 11.652 \\
\hline 2 & 2.0 & 18 & 10 & 0.0309 & 0.887 & 23.416 \\
\hline 3 & 1.5 & 20.5 & 15 & 0.0626 & 1.749 & 28.733 \\
\hline 4 & 2.0 & 20.5 & 12.5 & 0.0504 & 1.646 & 16.176 \\
\hline 5 & 2.0 & 20.5 & 12.5 & 0.0446 & 1.537 & 23.190 \\
\hline 6 & 2.5 & 20.5 & 15 & 0.0569 & 2.013 & 7.692 \\
\hline 7 & 2.0 & 20.5 & 12.5 & 0.0540 & 1.065 & 7.013 \\
\hline 8 & 2.0 & 18 & 15 & 0.0392 & 0.454 & 18.439 \\
\hline 9 & 2.0 & 20.5 & 12.5 & 0.0496 & 1.870 & 17.986 \\
\hline 10 & 2.5 & 20.5 & 10 & 0.0573 & 1.733 & 16.968 \\
\hline 11 & 2.0 & 23 & 15 & 0.0694 & 1.956 & 13.235 \\
\hline 12 & 2.0 & 20.5 & 12.5 & 0.0531 & 1.553 & 14.367 \\
\hline 15 & 2.0 & 23 & 10 & 0.0541 & 1.557 & 20.249 \\
\hline 16 & 2.5 & 23 & 12.5 & 0.0566 & 1.727 & 19.231 \\
\hline 17 & 1.5 & 20.5 & 10 & 0.0584 & 1.688 & 13.801 \\
\hline
\end{tabular}

DPP-4: Dipeptidyl peptidase-4, GAE: Gallic acid equivalent

Table 4: ANOVA for response surface quadratic model

\begin{tabular}{|c|c|c|c|c|c|}
\hline Source & Sum of squares & df & Mean Square & F-value & p-value Prob $>$ F \\
\hline Model & $1.820 \mathrm{E}-003$ & 9 & $2.022 \mathrm{E}-004$ & 9.74 & 0.0033 \\
\hline $\mathrm{X}_{1}$ & 1.217E-004 & 1 & 1.217E-004 & 5.86 & 0.0460 \\
\hline$X_{2}^{1}$ & $9.385 \mathrm{E}-005$ & 1 & $9.385 \mathrm{E}-005$ & 4.52 & 0.0711 \\
\hline $\mathrm{X}_{3}^{2}$ & $1.295 \mathrm{E}-003$ & 1 & $1.295 \mathrm{E}-003$ & 62.38 & $<0.0001$ \\
\hline $\mathrm{X}_{1}^{3} \mathrm{X}_{2}$ & $5.290 \mathrm{E}-006$ & 1 & $5.290 \mathrm{E}-006$ & 0.25 & 0.6293 \\
\hline $\mathrm{X} 1 \mathrm{X}_{3}^{2}$ & 3.721E-005 & 1 & $3.721 \mathrm{E}-005$ & 1.79 & 0.2225 \\
\hline $\mathrm{X}_{2} \mathrm{X}_{3}^{3}$ & $1.225 \mathrm{E}-005$ & 1 & $1.225 \mathrm{E}-005$ & 0.59 & 0.4676 \\
\hline $\mathrm{X}_{2}^{2}$ & $1.085 \mathrm{E}-005$ & 1 & $1.085 \mathrm{E}-005$ & 0.52 & 0.4933 \\
\hline $\mathrm{X}_{3}^{2}$ & 5.291E-005 & 1 & $5.291 \mathrm{E}-005$ & 2.55 & 0.1545 \\
\hline Residual & $1.454 \mathrm{E}-004$ & 7 & $2.077 \mathrm{E}-005$ & - & - \\
\hline Lack of fit & $9.085 \mathrm{E}-005$ & 3 & $3.028 \mathrm{E}-005$ & 2.22 & 0.2280 \\
\hline Pure error & 5.451E-005 & 4 & 1.363E-005 & - & - \\
\hline Cor. total & $1.965 \mathrm{E}-003$ & 16 & - & - & - \\
\hline \multicolumn{6}{|c|}{$\begin{array}{l}\text { Standard deviation }=4.557 \mathrm{E}-003 ; \text { Mean }=0.05 ; \mathrm{C} . \mathrm{V} \%=8.65 \\
\mathrm{R}^{2}=0.8781 ; \text { Adj } \mathrm{R}^{2}=0.8309\end{array}$} \\
\hline
\end{tabular}

ANOVA: Analysis of variance 
Statistical analysis

The experimental data were examined using multivariate regression analysis. The regression model was obtained by a quadratic model in terms of coded variables approximating the efficiency of the reactive extraction process, which can be written as follows:

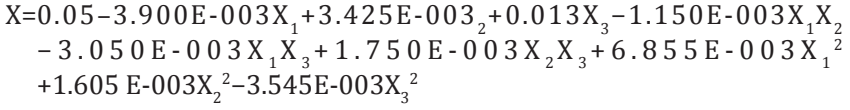

The model was subjected to analysis of variance (ANOVA) as shown in Table 4. The ANOVA showed that the model's F-value was 9.74 and its $p$-value was significant at $0.033(\mathrm{p}<0.05)$, with $\mathrm{A}, \mathrm{C}$, and $\mathrm{A}^{2}$ being significant model terms. The $\mathrm{R}^{2}$ value was 0.926 , which implied that $92.6 \%$ of the variation could be explained by this model. The F-value for lack of fit $(\mathrm{p}>0.05)$ was 2.22 , showing non-significant real error. The significance of the F-value of 0.228 lack of fit with $p>0.05$ was statistically non-significant.

The optimal conditions in this study were suggested based on the results of RSM analysis using Design-Expert ${ }^{\circledR}$ v.10.0.03 software as follows: Extraction time $15 \mathrm{~min}$, [bmim]Br concentration $1.5 \mathrm{~mol} / \mathrm{l}$, and solvent-to-sample ratio $23 \mathrm{~mL} / \mathrm{g}$.

\section{CONCLUSION}

According to suggestions from data analysis, the optimal conditions of IL [bmim] Br-based MAE in trans-resveratrol extraction from melinjo seeds from this experiment were as follows: Solvent concentration [bmim] $\mathrm{Br} 1.5 \mathrm{M}$, solvent-to-sample ratio $23 \mathrm{~mL} / \mathrm{g}$, and extraction time 15 min. Meanwhile, the highest level was 1.9562 mgGAE/g melinjo seed powder, whereas the highest percentage inhibition obtained was $28.73 \%$.

\section{ACKNOWLEDGMENTS}

Thanks Directorate of Research and Community Engagement, Universitas Indonesia for financial support via PITTA Grant 2017.

\section{CONFLICTS OF INTEREST}

All authors declare that they have no conflicts of interest.

\section{REFERENCES}

1. World Health Organization. Definition, Diagnosis and Classification of Diabetes Mellitus and its Complications. Part 1: Diagnosis and Classification of Diabetes Mellitus. Geneva: Department of Noncommunicable Disease Surveillance; 2009.

2. Geetha P, Shanmugasundharam P. Drug utilization evaluation of antidiabetic drugs among Type 2 diabetes patients of Tamil Nadu. Asian J Pharm Clin Res 2017;10:202-5.

3. Patel B, Ghate M. Recent approaches to medicinal chemistry and therapeutic potential of dipeptidyl peptidase-4 (DPP-4) inhibitors. Eur J Med Chem 2014;74:574-605.

4. Anhê F, Desjardins Y, Pilon G, Dudonné S, Genovese M, Lajolo F, et al. Polyphenols and Type 2 diabetes: A prospective review. Pharmanutrition 2013;1 Suppl 4:105-14.

5. Mahapatra D, Asati V, Bharti S. ChemInform abstract: Chalcones and their therapeutic targets for the management of diabetes: Structural and pharmacological perspectives. Cheminform 2015;46 Suppl:15.

6. Peng C, Yang Y, Chan K, Wang C, Chen M, Huang C. Hibiscus sabdariffa Polyphenols alleviate insulin resistance and renal epithelial to mesenchymal transition: A novel action mechanism mediated by Type 4 dipeptidyl peptidase. J Agric Food Chem 2014;62 Suppl 40:9736-43.

7. Zhang B, Yang R, Liu CZ. Microwave assisted extraction of chlorogenic acid from flower buds of Lonicera japonica Thunb. Sep Purif Technol
2008;62:480-3

8. Udenigwe CC, Ramprasath VR, Aluko RE, Jones PJ. Potential of resveratrol in anticancer and anti-inflammatory therapy. Nutritrion 2008;66:445-54

9. Elíes J, Cuínnas A, MacDougall DA, Leiro J, Campos-Toimil M. Trans-resveratrol down-regulates caveolin-1, up-regulates endothelial NO synthase and reduces their interaction in vascular smooth muscle andendothelial cells. Food Biosci 2013;1:31-8.

10. Kundu JK, Surh YJ. Cancer chemopreventive and therapeutic potential of resveratrol: Mechanistic perspectives. Cancer Lett 2008;269:243-61.

11. Brasnyo P, Molnar GA, Mohas M, Markó L, Laczy B, Cseh J, et al. Resveratrol improves insulin sensitivity, reduces oxidative stress and activates the akt pathway in Type 2 diabetic patients. Br J Nutr 2011;20:1-7.

12. Iliya I, Ali Z, Tanaka T, Iinuma M. Stilbene derivatives from Gnetum gnemon Linn. Phytochemistry 2002;62:601-6.

13. Mun'im A, Munadhil MA, Puspitasari N, Azminah A, Yanuar A. Angiotensin converting enzyme inhibitory activity of melinjo (Gnetum gnemon L.) seed extracts and molecular docking of its stilbene constituents. Asian J Pharm Clin Res 2017;10:243-8.

14. Kato E, Tokunaga Y, Sakan F. Stilbenoids isolated from seeds of melinjo (Gnetum gnemon L.) and their biological activity. J Agric Food Chem 2009;2009:2544-9

15. Hemwimon S, Pavasant P, Shotipruk A. Microwave- assisted extraction of antioxidative anthraquinones from roots of Morinda citrifolia. Sep Purif Technol 2007;54:44-50

16. Xiao W, Han L, Shi B. Microwave-assisted extraction of flavonoids from Radix Astragali. Sep Purif Technol 2008;62:614-8.

17. Du FY, Xiao X, Li G. Application of ionic liquids in the microwaveassisted extraction of trans-resveratrol from rhizma polygoni cuspidati. J Chromatogr A 2007;1140:56-62.

18. Du FY, Xiao XH, Luo XJ, Li GK. Application of ionic liquids in the microwave-assisted extraction of polyphenolic compounds from medicinal plants. Talanta 2009;78:1177-84.

19. Bobo-García G, Davidov-Pardo G, Arroqui C, Vírseda P, Marín-Arroyo MR, Navarro M. Intra-laboratory validation of microplate methods for total phenolic content and antioxidant activity on polyphenolic extracts, and comparison with conventional spectrophotometric methods. J Sci Food Agric 2015;95 Suppl 1:204-9.

20. Ahmad I, Yanuar A, Mulia K, Mun'im A. Optimization of ionic liquidbased microwave-assisted extraction of polyphenolic content from Peperomia pellucida (L) Kunth using response surface methodology. Asian Pac J Trop Biomed 2017;7 Suppl 7:660-5.

21. Souto HA, Carneiro MC, Seferin M, Senna MJH. Determination of trans-resveratrol concentrations in Brazilian red wines by HPLC. J Food Compos Anal 2001;14:441-5

22. Wazir D, Ahmad S, Muse R. Antioxidant activities of different parts of Gnetum gnemon L. J Plant Biochem Biotechnol 2011;20:234-40.

23. Thomas L, Eckhardt M, Langkopf E, Tadayyon M, Himmelsbach F, Mark M. (R)-8-(3-Amino-piperidin-1-yl)-7-but-2-ynyl-3-methyl1-(4-methyl-quinazolin-2-ylmethyl)-3,7-dihydro-purine-2,6-dione (BI 1356), a novel xanthine-based dipeptidyl peptidase 4 inhibitor, has a superior potency and longer duration of action compared with other dipeptidyl peptidase-4 inhibitors. J Pharm Exp Ther 2008;325 Suppl 1:175-82.

24. Fan J, Johnson M, Lila M, Yousef G, de Mejia E. Berry and citrus phenolic compounds inhibit dipeptidyl peptidase IV: Implications in diabetes management. Evid Based Complementary Altern Med 2013;2013:1-13.

25. El Meligy S, El Batch M, Abd El Alem G. Effect of resveratrol on dipeptidyl peptidase-4 (DPP-4) and phospho enol pyruvate carboxy kinase (PEPCK) in streptozotocin -induced diabetic rats. Researchgate 2011;3:1-14.

26. Borde MK, Suman RK, Mohanty IR, Deshmukh YA. Dipeptidyl peptidase-iv inhibitory activities of medicinal plants: Terminalia arjuna, Commiphora mukul, Gymnema sylvestre, Morinda citrifolia, Emblica officinalis. Asian J Pharm Clin Res 2016;9:180-2.

27. Mandal V, Mohan Y, Hemalatha S. Microwave assisted extraction - An innovative and promising extraction tool for medicinal plant research. Pharm J 2006;1 Suppl 1:2-11 